\title{
6. Use of Archives in Nuclear Arms Control and Disarmament Research Nancy Teeple
}

Nancy Teeple is an adjunct assistant professor and research associate at the Department of Political Science and Economics at the Royal Military College of Canada. She is a member of the DND MINDS North American and Arctic Defence and Security Network (NAADSN), where she held the 2020-2021 NAADSN Postdoctoral Fellowship. She also recently held the 2019-2020 Fulbright Canada Research Chair in Peace and War Studies at Norwich University in Vermont. Dr. Teeple recently authored "Offensive Weapons and the Future of Arms Control," in the Canadian Journal of European and Russian Studies 14(1): 79-102.

nancy.teeple@rmc-cmr.ca

In exploring Canada's activity in promoting nuclear arms control, non-proliferation and

disarmament, my research involved consulting academic, think tank/foundation, media and

government sources. Among the government sources consulted were online archived

documents - reports and analyses on Canada's historic role in this area of foreign policy. As this

research moves forward, in order to make comparisons with Canada's current activity with that

of the past, further archival consultation will be required. These documents reveal the context

within which Canada found itself active in promoting arms control, non-proliferation and

disarmament (such as during the Pierre Elliot Trudeau government and the post-Cold War

1990s when nuclear weapons played less of a role in states' national security strategies).

Archival material, including standing committee reports, provides a view of the role of specific

actors within such contexts, such as key players in Foreign/External Affairs Canada.

The context revealed in these archival documents demonstrate the interplay of actors

and other variables within the domestic and international environment. This interplay is unique 
and circumstantial, shaped by the important issues and events of the time, the agendas of the key actors in promoting (or stepping back from) active arms control and disarmament, in addition to other influences such as public opinion. Essentially, these materials capture a snapshot of where the issues and actors stood at that point in time, providing a comparison for the unfolding of events and subsequent shifts in behaviours. These snapshots show a step in the process in which the current state of play emerged; thus, such archival documents provide value to path-dependence and process-tracing methodologies.

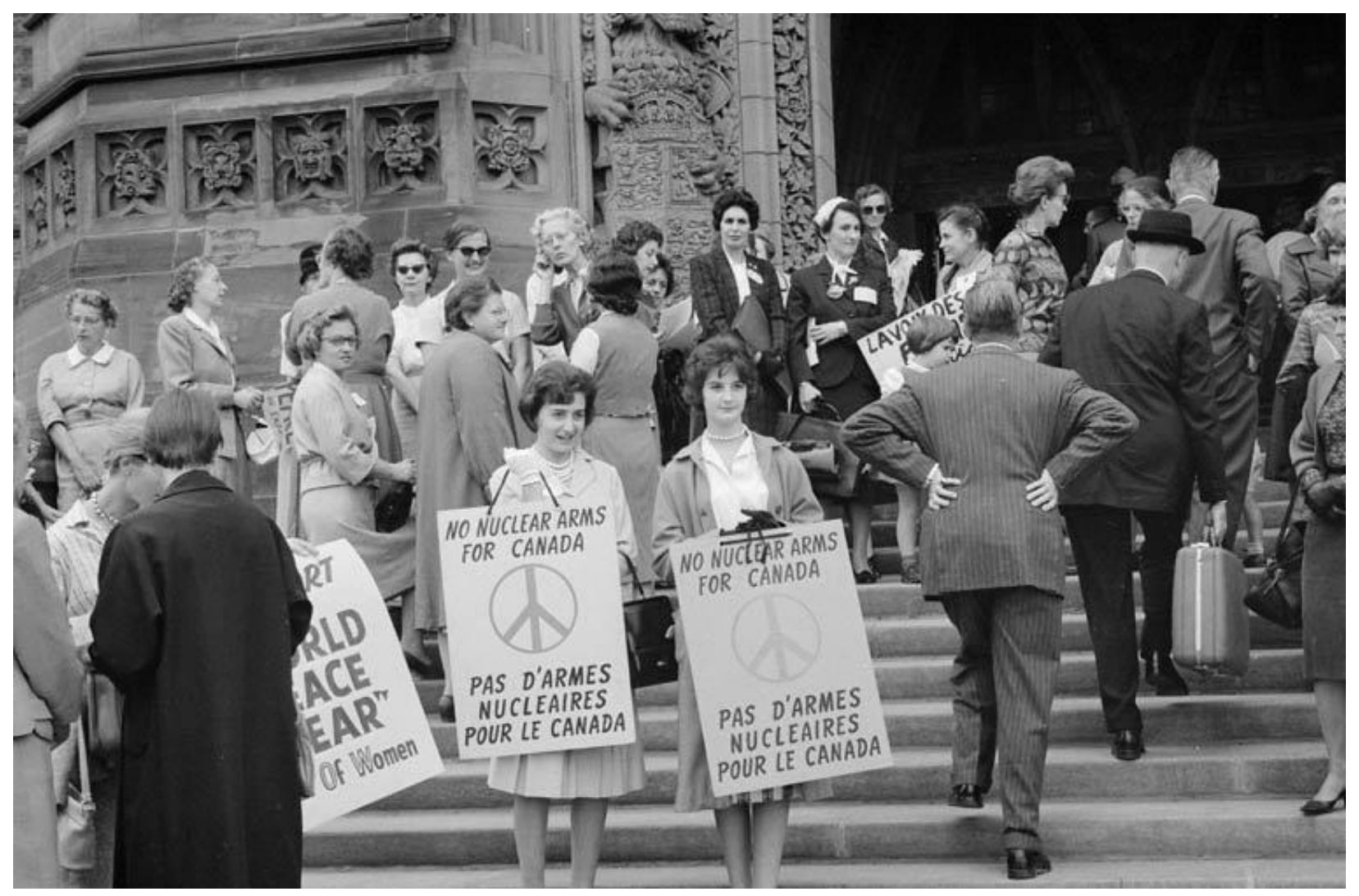

Figure 3. Women on steps holding signs "No Nuclear Arms for Canada - Pas d'armes nucléaires pour le Canada," September 25, 1961. Canada has a long tradition of promoting nuclear arms control and disarmament. (Duncan Cameron. Library and Archives Canada, Reference No. MIKAN 3592131, Ottawa Ontario Canada. https://www.flickr.com/photos/lac-bac/7797421452. Used under CC-BY-NC-ND license.) 
The availability of online archival government documents facilitates data collection and encourages further consultation of such reference materials. This is particularly important to scholars located far from the National Capital Region - it saves time from traveling to access hard copy archival documents or sending requests through Access to Information, a convoluted and costly process through the postal system. These online collections are not complete, and thus much valuable information is only available through application requests. It is hoped that with increasing digitization of such documents, the process will be streamlined and researchers may reduce the time required to access the materials. 